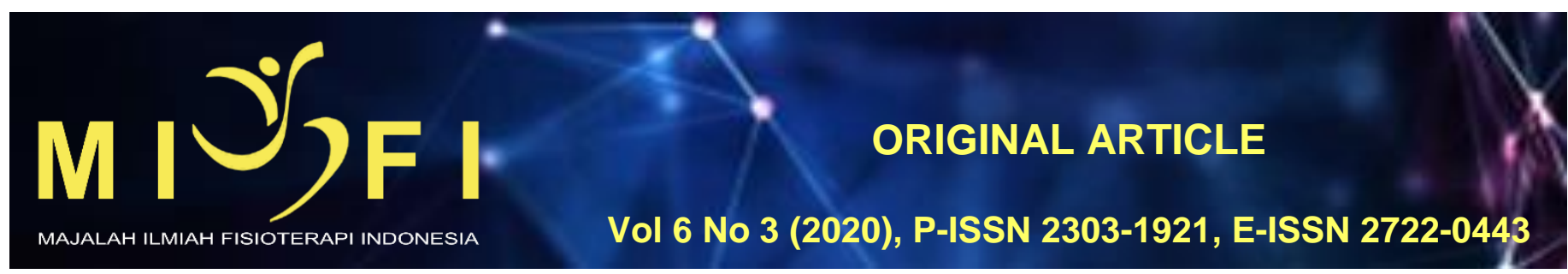

\title{
HUBUNGAN NYERI BAHU DENGAN ROUNDED SHOULDER POSTURE PADA MAHASISWA PENGGUNA KOMPUTER DI SEKOLAH TINGGI DESAIN BALI
}

\author{
I Gusti Ayu Bulan Sistayani ${ }^{1}$, Ari Wibawa ${ }^{2}$, Luh Putu Ratna Sundari ${ }^{3}$, Agung Wiwiek Indrayani ${ }^{4}$ \\ ${ }^{1}$ Program Studi Sarjana Fisioterapi dan Profesi Fisioterapi, Fakultas Kedokteran, Universitas Udayana, Denpasar, Bali \\ 2Departemen Fisioterapi, Fakultas Kedokteran, Universitas Udayana, Denpasar, Bali \\ ${ }^{3}$ Departemen IImu Faal, Fakultas Kedokteran, Universitas Udayana, Denpasar, Bali \\ ${ }^{4}$ Departemen Farmakologi dan Terapi, Fakultas Kedokteran, Universitas Udayana, Denpasar, Bali \\ igustiayubulansistayani@gmail.com
}

\begin{abstract}
ABSTRAK
Nyeri bahu merupakan salah satu penyebab terjadinya morbiditas dengan prevalensi yang tinggi. Nyeri bahu dan leher berhubungan dengan postur statis serta mempertahankan leher dalam posisi menekuk ke depan. Posisi kepala yang lebih ke depan menyebabkan adanya kompensasi berupa bahu bergerak ke depan yang mengindikasikan adanya Rounded ShoulderPosture (RSP). RSP merupakan salah satu postur janggal pada pengguna komputer. Sekolah Tinggi Desain Bali merupakan salah satu sekolah tinggi dengan pelajaran desain yang mengahruskan penggunaan komputer selama berjam - jam. Tujuan penelitian ini adalah untuk mengetahui hubungan nyeri bahu dengan Rounded Shoulder Posture pada mahasiswa pengguna komputer di Sekolah Tinggi Desain Bali. Penelitian ini merupakan penelitian analitik observasional dengan desain cross-sectional. Jumlah sampel penelitian adalah 42 orang mahasiswa pengguna komputer atau laptop. Teknik analisa yang digunakan yaitu uji Spearman Rank. Hasil penelitian menunjukkan bahwa nilai $p=0,156$ pada RSP kanan dan $p=0,673$ pada RSP kiri yang mengindikasikan bahwa tidak ada hubungan nyeri bahu dengan RSP. Beberapa faktor yang menyebabkan hal tersebut adalah tidak ada perbedaan postur antara individu dengan nyeri bahu dan tanpa nyeri bahu, ketidakseimbangan otot yang bersifat fungsional, mobilitas dan fleksibilitas, serta adapatasi tubuh terhadap nyeri. Berdasarkan hasil penelitian, maka dapat disimpulkan bahwa tidak ada hubungan nyeri bahu dengan Rounded Shoulder Posture pada mahasiswa pengguna komputer di Sekolah Tinggi Desain Bali.
\end{abstract}

Kata Kunci : nyeri bahu, rounded shoulder posture, pengguna komputer, mahasiswa, Bali

\section{CORRELATION BETWEEN SHOULDER PAIN AND ROUNDED SHOULDER POSTURE IN STUDENT COMPUTER USERS IN SEKOLAH TINGGI DESAIN BALI}

\section{ABSTRACT}

Shoulder pain is one of the causes of morbidity with high prevalence. Neck and shoulder pain is related to static posture and maintaining the neck in a bent forward position. A more forward head position results in compensation in the form of forwarding shoulder which indicates Rounded Shoulder Posture (RSP). RSP is one of awkward posture in computer users. Sekolah Tinggi Desain Bali is one of the academy with a design class that requires hours of computer use. This study aimed to know the correlation between shoulder pain and Rounded Shoulder Posture in student computer users in Sekolah Tinggi Desain Bali. This study was an observational analytic study with a cross-sectional design. The total sample of this study was 42 student computer users or laptop. The analysis technique which was used in this study is the Spearman rank test. The results showed that the value of $p=0,156$ in the right $R S P$ and $p=0,673$ in the left RSP indicating that there was no association between shoulder pain with RSP. Several factors cause this result were no differences in posture between individuals with shoulder pain and without shoulder pain, functional muscle imbalances, mobility and flexibility, and body adaptation to pain. Based on the results of this study, it can be concluded that there was no correlation between shoulder pain and Rounded Shoulder Posture in student computer users in Sekolah Tinggi Desain Bali.

Keywords: shoulder pain, rounded shoulder posture, computer users, students, Bali

\section{PENDAHULUAN}

Nyeri merupakan salah satu hal yang dapat mempengaruhi aktivitas dan partisipasi seseorang dalam kehidupan sehari - hari. Seseorang dengan keluhan nyeri memungkinkan terjadinya penurunan fungsi dan keterbatasan gerak sehingga akhirnya berdampak pada produktivitasnya. Oleh sebab itu, mencegah serta menangani faktor - faktor yang berhubungan dengan kejadian nyeri merupakan hal yang penting sehingga seseorang dapat beraktivitas secara optimal.

Nyeri bahu merupakan salah satu penyebab terjadinya morbiditas dengan prevalensi yang tinggi. ${ }^{1}$ Selain itu, nyeri bahu juga dapat mempengaruhi beban ekonomi, menyebabkan kerugian individu serta mempengaruhi pekerjaan dan kehidupan pribadi. ${ }^{2}$

Studi prevalensi yang dilakukan pada tenaga kesehatan gigi di fakultas kedokteran gigi, Universitas Mahidol Bangkok pada tahun 2008 - 2009 menunjukkan bahwa nyeri bahu merupakan nyeri muskuloskeletal dengan angka 
prevalensi tertinggi yaitu sebesar $72,2 \%{ }^{3}$ sedangkan studi prevalensi pada ibu rumah tangga di Iran pada tahun 2014 menunjukkan bahwa nyeri bahu memiliki angka prevalensi tertinggi ketiga, yaitu sebesar $41,5 \% .{ }^{4}$ Menurut Lumunon et al., beberapa pekerjaan yang berisiko terjadi nyeri bahu salah satunya adalah orang - orang yang bekerja selama berjam - jam di depan komputer. ${ }^{5}$ Studi prevalensi pada mahasiswa yang bekerja dengan komputer selama 3 tahun di Ferdowsi University of Mashhad pada tahun 2015 memperlihatkan hasil prevalensi gangguan muskuloskeletal dalam 3 tahun terakhir salah satunya adalah nyeri bahu yaitu mencapai angka $100 \%{ }^{6}$ serta penelitian prevalensi nyeri bahu pada karyawan bank pengguna komputer di India pada tahun 2014 sebesar 15,2\%. ${ }^{7}$ Prevalensi konsultasi tahunan untuk diagnosis nyeri bahu di Swedia pada tahun 2006 dilaporkan sebesar 1\% pada populasi dewasa baik wanita maupun pria. $^{2}$

Nyeri bahu dan leher berhubungan dengan postur statis serta mempertahankan leher dalam posisi menekuk ke depan. ${ }^{8}$ Posisi kepala yang lebih ke depan menyebabkan perubahan pada pusat gravitasi tubuh. Oleh sebab itu, sebagai kompensasi perubahan tersebut, tubuh bagian atas bergerak ke belakang dan bahu bergerak ke depan sehingga kepala berada di depan dari trunk. ${ }^{9}$ Posisi bahu yang terkulai ke depan mengindikasikan adanya Rounded Shoulder Posture (RSP). ${ }^{10}$

RSP merupakan postur tubuh yang membungkuk dimana skapula mengalami elevasi dan akromion menjulur ke depan. ${ }^{11}$ Studi prevalensi pada staf gigi di Tehtran University of Medical Science pada tahun 2012 - 2013 menunjukkan kejadian rounded shoulder sebanyak $68,8 \% .{ }^{12}$ RSP disebabkan oleh ketegangan otot - otot pektoralis atau kelemahan otot - otot stabilisator skapula dan kebiasaan. ${ }^{10}$

Penggunaan komputer dalam posisi yang tidak tepat dalam jangka waktu yang lama menyebabkan centerline kepala berpindah ke depan dan ke atas yang mengakibatkan peningkatan berat kepala yang ditopang oleh leher dan akhirnya menyebabkan perubahan pada kepala, leher dan area yang berhubungan dengan bahu. ${ }^{11}$ Postur yang janggal pada pengguna komputer ditandai salah satunya adalah memiliki RSP. ${ }^{13}$ Penelitian pada pekerja kantoran dengan dan tanpa nyeri leher di Tehran University of Medical Science pada tahun 2011 - 2012 menunjukkan bahwa 78,3\% dari 101 pekerja kantor yang bekerja dengan komputer memiliki RSP. ${ }^{14}$

RSP merupakan salah satu karakteristik penyimpangan postur yang terjadi pada upper crossed syndrome (UCS) oleh karena ketidakseimbangan otot. UCS ditandai dengan adanya ketegangan pada upper trapezius dan levator scapula pada sisi belakang yang menyilang dengan ketegangan pada pectoralis major dan minor serta kelemahan pada deep cervical flexor yang menyilang dengan kelemahan pada middle dan lower trapezius. Karakteristik penyimpangan postur yang terjadi pada UCS oleh karena ketidakseimbangan otot, yaitu forward head posture, rounded shoulder, dan scapular winging dan protraction. ${ }^{15}$

Forward head and rounded shoulder posture oleh karena perkerjaan di depan dan di bawah level mata menyebabkan peningkatan gaya pada otot upper trapezius dan levator scapulae sehingga stress yang ditimbulkan mengakibatkan iskemik dan nyeri pada otot - otot yang bekerja secara berlebihan. ${ }^{3}$ Hiperaktivitas upper trapezius berhubungan forward head dan RSP. ${ }^{15}$ Peningkatan aktivasi otot upper trapezius dapat menyebabkan peningkatan nyeri servikal dan bahu. ${ }^{16}$

Penggunaan komputer secara intensif seringkali dilakukan oleh mahasiswa terutama pada mahasiswa desain. Sekolah Tinggi Desain (STD) Bali merupakan salah satu sekolah tinggi di Bali yang berfokus pada bidang desain. Oleh sebab itu, mahasiswa di STD Bali memiliki risiko mengalami nyeri bahu dan RSP.

Berdasarkan latar belakang tersebut, peneliti ingin mengetahui hubungan nyeri bahu dengan Rounded Shoulder Posture pada mahasiswa pengguna komputer di Sekolah Tinggi Desain Bali.

\section{METODE}

Penelitian ini menggunakan penelitian desain analitik observasional dengan pendekatan cross-sectional yang dilaksanakan di Sekolah Tinggi Desain Bali pada bulan April 2019. Jumlah sampel penelitian adalah sebanyak 42 orang mahasiswa pengguna computer atau laptop yang memenuhi kriteria inklusi yaitu sehat jasmani dan rohani, berusia 21 - 25 tahun, jenis kelamin laki - laki dan perempuan, indeks aassa tubuh kategori underweight sampai normal, merupakan mahasiswa Sekolah Tinggi Desain Bali, menggunakan komputer, laptop, notebook, personal computer $\geq 4$ jam per hari, koorperatif dan bersedia menjadi subjek penelitian dari awal hingga akhir penelitian dengan menandatangani informed consent. Sampel tidak memenuhi kriteria apabila memenuhi kriteria ekslusi yaitu memiliki riwayat kecelakaan dan cedera pada bahu, memiliki riwayat operasi pada bahu, memiliki riwayat dislokasi dan atau fraktur pada bahu, adanya cedera akut pada bahu, nyeri menjalar dari leher akibat spondylosis, dan sedang menjalani perawatan fisioterapi. Teknik pengambilan sampel yang digunakan adalah purposive sampling.

Pemeriksaan keluhan muskuloskeletal dilakukan dengan menggunakan Standardized Nordic Questionnaire $(\mathrm{SNQ})^{17}$ sedangkan pemeriksaan Round Shoulder Posture dilakukan dengan metode supinasi. Subjek berada pada posisi supinasi yang rileks dan nyaman dengan kedua tangan berada pada posisi netral.. Pemeriksaan dilakukan dengan mengukuru jarak antara acromion pada sendi bahu dengan permukaan meja dengan menggunakan vernier caliper dan hasil yang didapat adalah rata - rata dari 3 kali pemeriksaan. ${ }^{18}$. Data dianalisis dengan menggunakan software SPSS.

\section{HASIL}

Karakteristik sampel berdasarkan usia, jenis kelamin, indeks masa tubuh, dan durasi kerja 
Tabel 1. Distribusi Karakteristik Sampel berdasarkan Usia,

Jenis Kelamin, Indeks Masa Tubuh, dan Durasi Kerja dengan Komputer

\begin{tabular}{lcc}
\hline Variabel & Frekuensi (n) & Persentase (\%) \\
\hline Usia & & \\
21 & 28 & 66,7 \\
22 & 8 & 19,0 \\
23 & 3 & 7,1 \\
25 & 3 & 7,1 \\
Jenis Kelamin & & \\
Laki-laki & 24 & 57,1 \\
Perempuan & 18 & 42,9 \\
IMT & & \\
Underweight & 14 & 33,3 \\
Normal & 28 & 66,7 \\
Durasi kerja & & \\
4 jam/hari & 6 & 14,3 \\
5 jam/hari & 6 & 14,3 \\
6 jam/hari & 11 & 26,2 \\
7 jam/hari & 3 & 7,1 \\
8 jam/hari & 9 & 21,4 \\
10 jam/hari & 1 & 2,4 \\
12 jam/hari & 5 & 11,9 \\
13 jam/hari & 1 & 2,4 \\
\hline
\end{tabular}

Berdasarkan tabel di atas maka diketahui sampel terbanyak ialah pada usia 21 tahun yakni sejumlah 28 orang $(66,7 \%)$, sedangkan berdasarkan jenis kelamin, jumlah sampel laki -laki lebih banyak dibandingkan sampel perempuan. Jumlah sampel laki - laki sebanyak 24 orang (57,1\%) dan sampel perempuan sebanyak 18 orang (42,9\%).

Sampel penelitian merupakan individu dengan indeks massa tubuh kategori underweight dan normal. Berdasarkan data distribusi sampel, diketahui sampel dengan kategori underweight berjumlah 14 orang $(33,3 \%)$ sedangkan sampel dengan kategori normal berjumlah 28 orang $(66,7 \%)$. Sampel dengan durasi penggunaan komputer selama 6 jam per hari merupakan sampel dengan jumlah terbanyak yaitu sebanyak 11 orang $(26,2 \%)$.

Tabel 2. Distribusi Karakteristik Sampel Berdasarkan Gangguan Muskuloskeletal

\begin{tabular}{lccc}
\hline \multicolumn{1}{c}{ Variabel } & & Frekuensi (n) & Persentase (\%) \\
\hline Gangguan Muskuloskeletal & Ya & 31 & \\
Leher & Tidak & 11 & 73,8 \\
& Ya & 19 & 26,2 \\
Bahu & Tidak & 23 & 45,2 \\
\multirow{4}{*}{ Punggung Atas } & Ya & 23 & 54,8 \\
& Tidak & 19 & 54,8 \\
Siku & Ya & 8 & 45,2 \\
\multirow{2}{*}{ Pergelangan Tangan / Tangan } & Tidak & 34 & 19,0 \\
\multirow{2}{*}{ Punggung Bawah } & Tidak & 21 & 81,0 \\
\multirow{2}{*}{ Pinggul / Paha } & Ya & 24 & 50,0 \\
\multirow{2}{*}{ Lutut } & Tidak & 18 & 50,0 \\
\multirow{2}{*}{ Pergelangan Kaki / Kaki } & Ya & 17 & 57,1 \\
& Tidak & 25 & 42,9 \\
& Ya & 13 & 40,5 \\
& Tidak & 29 & 39,5 \\
& Ya & 16 & 69,0 \\
& Tidak & 26 & 38,1 \\
\end{tabular}

Tabel 2. menunjukkan distribusi karaktersitik sampel berdasarkan gangguan musculoskeletal. Berdasarkan tabel tersebut, dapat dilihat bahwa dari 42 orang sampel terdapat 19 orang $(45,2 \%)$ mengalami gangguan muskuloskeletal pada daerah bahu dan 23 orang $(54,8 \%)$ tidak mengalami gangguan muskuloskeletal pada daerah bahu. Gangguan muskuloskeletal terbanyak terjadi pada daerah leher yaitu 31 orang $(73,8 \%)$ sedangkan hanya 11 orang $(26,2 \%)$ yang tidak mengalami gangguan muskuloskeletal pada daerah leher. Sebaliknya, sebanyak 8 orang $(19,0 \%)$ mengalami keluhan pada siku dan 34 orang $(81,0 \%)$ tidak mengalami keluhan pada siku. Hal ini menunjukkan bahwa keluhan pada siku merupakan keluhan terkecil.

Tabel 3. Distribusi Karakteristik Sampel Berdasarkan Rounded Shoulder Posture

\begin{tabular}{lccc}
\hline Variabel & & Rerata $(\mathbf{m m})$ & Simpang Baku \\
\hline \multirow{2}{*}{ Rounded Shoulder Posture } & Kanan & 79,345 & 124,767 \\
& Kiri & 73,417 & 126,356 \\
\hline
\end{tabular}


Berdasarkan tabel 3., diketahui bahwa rerata nilai Rounded Shoulder Posture kanan dan kiri berturut - turut dari 42 orang sampel yaitu $79,345 \mathrm{~mm}$ dan $73,417 \mathrm{~mm}$.

Tabel 4. Hubungan Nyeri Bahu dengan Rounded Shoulder Posture Kanan

\begin{tabular}{lc}
\hline Korelasi Variabel & $\mathbf{p}$ \\
\hline Nyeri bahu dengan RSP kanan & 0,156 \\
Nyeri bahu dengan RSP kiri & 0,673 \\
\hline
\end{tabular}

Tabel 5. menunjukkan nilai signifikansi lebih dari $0,05(p>0,05)$, yaitu $p=0,156$ dan $p=0,673$ secara berturut turut. Hal ini berarti bahwa tidak terdapat hubungan nyeri bahu dengan Rounded ShoulderPosture.

\section{DISKUSI}

Hubungan nyeri bahu dengan Rounded Shoulder Posture diketahui berdasarkan hasil analisis uji korelasi Spearman rank oleh karena data bersifat kategori dan numerik. Berdasarkan hasil uji analisis, didapatkan nilai signifikansi lebih dari 0,05 ( $p>0,05)$, yaitu $p=0,156$ untuk nyeri bahu dengan Rounded Shoulder Posture kanan dan $\mathrm{p}=0,673$ untuk nyeri bahu dengan Rounded Shoulder Posture kiri. Oleh sebab itu, hasil uji analisis menunjukkan bahwa tidak terdapat hubungan nyeri bahu dengan Rounded Shoulder Posture.

Penelitian yang sejalan dilakukan oleh Nijs et al. yang melakukan penelitian untuk mengetahui kegunaan klinis dari 3 pemeriksaan klinis yang digunakan untuk menilai posisi skapula pada penderita nyeri bahu. Hal tersebut diketahui dengan menganalisis hubungan antara hasil dari pemeriksaan dengan tingkat kesakitan dan ketidakmampuan yang dirasakan oleh penderita nyeri bahu. Hasil penelitian menunjukkan bahwa tidak ada hubungan antara keluhan dengan hasil dari penilaian posisi skapula pada sisi bahu yang sakit. ${ }^{19}$ Penilaian posisi skapula pada penelitian tersebut salah satunya adalah dengan mengukur jarak antara sisi posterior akromion dengan meja yang merupakan pengukuran untuk menentukan RSP.

Tidak adanya hubungan antara nyeri bahu dengan RSP diduga oleh karena tidak ada perbedaan postur antara individu dengan nyeri bahu dan tanpa nyeri bahu. Hal ini sesuai dengan penelitian yang dilakukan oleh Nijs et al. menunjukkan bahwa tidak terdapat perbedaan yang signifikan antara sisi bahu dengan keluhan dengan sisi bahu tanpa keluhan walaupun sisi bahu dengan keluhan menunjukkan nilai rata - rata yang lebih besar pada beberapa pemeriksaan. ${ }^{19}$ Penelitian lain yang menunjukkan hal serupa dilakukan oleh Greenfield et al. yang menyatakan bahwa tidak ada perbedaan yang signifikan pada skapula protraksi, rotasi dan simetris antara individu dengan nyeri bahu dengan individu tanpa nyeri bahu. ${ }^{20}$

Hal lain yang dapat menjelaskan hasil penelitian ini adalah ketidakseimbangan otot yang dapat bersifat fungsional. Menurut Page et al., postur berhubungan dengan ketidakseimbangan otot dan fungsi walaupun hubungan sebab akibatnya belum dapat dipastikan. Ketidakseimbangan otot terjadi ketika perpanjangan atau kekuatan dari otot agonis dan antagonis menghalangi fungsi normal dan dapat bersifat fungsional maupun patologis. Ketidakseimbangan otot yang menganggu fungsi normal disebut sebagai ketidakseimbangan patologi. Kondisi ini dapat menyebabkan disfungsi sendi dan menyebabkan nyeri walaupun dapat juga terjadi tanpa nyeri. Ketidakseimbangan otot yang bersifat fungsional terjadi sebagai respon dari adanya adaptasi pada pergerakan yang kompleks termasuk ketidakseimbangan pada kekuatan dan fleksibilitas dari otot antagonis. Contohnya atlet sepak bola yang memperlihatkan pola kekuatan dan fleksibilitas yang berbeda sesuai dengan posisinya serta atlet yang sering melakukan pergerakan tangan di atas kepala seperti perenang menunjukkan kekuatan internal rotasi yang lebih besar. Ketidakseimbangan fungsional harus diperhatikan sebelum kondisi tersebut menjadi patologis. ${ }^{15}$ Oleh sebab itu, dalam penelitian ini diduga RSP yang terjadi pada sampel peneltian merupakan ketidakseimbangan fungsional.

Konsep mengenai penyimpangan postur yang dapat menyebabkan kondisi nyeri merupakan konsep yang telah diterima secara umum. Namun, terdapat beberapa pertanyaan yang mempertanyakan konsep tersebut seperti mengapa banyak kasus penyimpangan postur yang terjadi tanpa adanya keluhan serta mengapa penyimpangan postur yang terlihat ringan dapat menimbulkan keluhan. Hal ini tergantung pada kekonstanan penyimpangan. Postur tubuh seseorang dapat menjadi sangat buruk, namun individu tersebut mungkin fleksibel dan dapat mengubah posisi tubuhnya sesegara mungkin. Seseorang mungkin memiliki postur yang baik, namun terdapat kekakuan atau ketegangan yang dapat membatasi mobilitas sehingga posisi tubuh tidak dapat diubah dengan mudah. Olehsebab itu, kemungkinan disfungsi yang signifikan berasal dari kurangnya mobiltas yang dapat dilihat dari pemeriksaan fleksibilitas dan mobilitas daripada pemeriksaan postur statis. ${ }^{20}$

Forward head dan Rounded Shoulder Posture (RSP) berhubungan dengan hiperaktivitas upper trapezius. ${ }^{15}$ Peningkatan aktivasi otot upper trapezius dapat menyebabkan peningkatan nyeri servikal dan bahu. ${ }^{16} \mathrm{Hal}$ ini berbeda dengan hasil penelitian yang menunjukkan tidak terdapat hubungan nyeri bahu dengan RSP. Adaptasi tubuh terhadap nyeri diduga mempengaruhi hasil penelitian. Hal ini sesuai dengan penelitian yang dilakukan oleh Rivai et al. yang menunjukkan bahwa terdapat pekerja pemecah batu yang memiliki tingkat risiko ergonomi tinggi namun memiliki keluhan musculoskeletal dengan tingkat risiko rendah. Rendahnya tingkat risiko tersebut disebabkan oleh karena tubuh telah mampu beradaptasi dengan postur janggal yang dilakukan dalam jangka waktu yang lama sehingga tubuh telah terbiasa merasakan nyeri yang diakibatkan oleh postur janggal tersebut. ${ }^{21}$

Faktor lain yang berkontribusi terhadap hasil penelitian ini adalah faktor tuntutan kerja, jenis kelamin, pergerakan berulang serta durasi kerja yang mempengaruhi keluhan nyeri bahu. Menurut Ranasinghe et al., pekerjaan yang berlebih berhubungan secara signifikan dengan keluhan bahu. ${ }^{22}$ Prediktor terjadinya nyeri bahu kronis pada followup selama 5 tahun adalah tuntutan kerja dan kontrol keputusan. ${ }^{23}$

Faktor jenis kelamin dapat mempengaruhi hasil penelitian olehkarena variabel jenis kelamin tidak dikontrol dalam penelitian ini. Menurut Bodin et al., insiden nyeri bahu ditemukan lebih tinggi pada wanita dibandingkan pada 
pria. Hal ini disebabkan oleh perbedaan paparan saat bekerja atau di rumah, perbedaan kekuatan otot, dan faktor risiko psikososial seperti dukungan sosial yang rendah dan stress. ${ }^{24}$ Secara umum, wanita memiliki $60 \%$ lebih sedikit kekuatan otot pada bahu dan lengan. ${ }^{25}$ Selain itu, wanita memiliki ambang batas nyeri yang lebih rendah dibandingkan dengan pria. Ambang tekanan nyeri meningkat sesuai dengan kekuatan otot. ${ }^{8}$

Penggunaan komputer secara intensif membutuhkan pergerakan berulang dari anggota gerak atas seperti mengetik dan memindah mouse serta membutuhkan aktivitas otot statis untuk mempertahankan lengan pada posisi yang stabil. Penggunaan komputer juga akan membebani otot - otot serta sendi - sendi pada leher, bahu, dan anggota gerak atas. ${ }^{26}$

Sampel penelitian merupakan individu dengan durasi jam kerja di depan komputer lebih atau sama dengan 4 jam per hari, namun, luasnya jangka waktu durasi jam kerja pada sampel dapat mempengaruhi hasil penelitian. Menurut Ranasinghe et al., durasi penggunaan komputer harian berhubungan dengan keluhan pada bahu. ${ }^{22}$ Peningkatan durasi penggunaan komputer harian juga berhubungan secara konsisten dengan keluhan dan keparahan. Penggunaan komputer dalam jangka waktu yang lama membutuhkan postur statis pada tubuh bagian atas. Otot - otot pada leher, bahu dan anggota gerak atas akan menerima beban berlebih dan mengalami cidera untuk menjaga postur statis. Postur yang tidak tepat oleh karena sudut pandang pada layar dan posisi kursi dan meja yang buruk menyebabkan jaringan lunak memendek dan mengakibatkan ketegangan, kelemahan dan kelelahan otot. ${ }^{26}$

Penelitian ini memiliki kelemahan yang diduga mempengaruhi hasil dari penelitian. Kelemahan tersebut yaitu beberapa faktor yang berhubungan dengan nyeri bahu yang tidak dikontrol dalam penelitian ini di antaranya yaitu jenis kelamin dan beban kerja serta pergerakan berulang yang tidak diperhatikan dalam penelitian ini. Oleh sebab itu, diharapkan untuk penelitian selanjutnya untuk dapat memperhatikan dan mengontrol variable - variable tersebut. Selain itu, penelitian selanjutnya juga dapat memperhatikan faktor mobilitas dan fleksibitas dibandingkan dengan postur statis oleh karena disfungsi yang signifikan berasal dari kurangnya mobilitas. Selain itu, penelitian selanjutnya dapat dilakukan pada komunitas umum, bukan pada komunitas dengan penggunaan komputer yang intensif.

\section{SIMPULAN}

Berdasarkan hasil analisis data yang telah dilakukan dan pembahasan yang telah dipaparkan, maka dapat disimpulkan bahwa tidak terdapat hubungan antara nyeri bahu dengan Rounded Shoulder Posture pada Mahasiswa Pengguna Komputer di Sekolah Tinggi Desain Bali.

\section{DAFTAR PUSTAKA}

1. Perez-Palomares, S., Oliván-Blázquez, B., Arnal-Burró, A. M., Mayoral-Del Moral, O., Gaspar-Calvo, E., De-LaTorre-Beldarraín, M. L., López-Lapena, E., Perez-Benito, M., Ara- Loriente V., dan Romo-Calvo, L. Contributions of myofascial pain in diagnosis and treatment of shoulder pain. A randomized control trial. BMC Musculoskeletal Disorders; 2009; 10(1): 1-7.

2. Tekavec, E., Jöud, A., Rittner, R., Mikoczy, Z., Nordander, C., Petersson, I. F., \& Englund, M. Population-based consultation patterns in patients with shoulder pain diagnoses. BMC Musculoskeletal Disorders; 2012; 13: $238-245$.

3. Dajpratham, P., Ploypetch, T., Kiattavorncharoen, S., \& Boonsiriseth, K. Prevalence and associated factors of musculoskeletal pain among the dental personnel in a dental school. Journal of the Medical Association of Thailand; 2010; 93(6): 714-721.

4. Fazli, B., Ansari, H., Noorani, M., Jafari, S. M., Sharifpoor, Z., \& Ansari, S. The Prevalence of Musculoskeletal Disorders and its Predictors among Iranians' Housewives. International Journal of Epidemiologic Research;2016; 3(1): 53-62.

5. Lumunon, S. N., Sengkey, L., \& Angliadi, E. Hubungan Gerakan Berulang Lengan dengan Terjadinya Nyeri Bahu pada Penata Rambut di Salon. E-Clinic; 2015; 3: 1-4.

6. Fathi, A. Prevalence Rate of Postural Damages, Disorders \&amp; Anomalies among Computer Users. Physical Treatment; 2016; 6(1): 59-65.

7. Moom, R. K., Sing, L. P., \& Moom, N. Prevalence of Musculoskeletal Disorder among Computer Bank Office Employees in Punjab (India): A Case Study. Procedia Manufacturing; 2015; 3: 6624-6631.

8. Yue, P., Liu, F., \& Li, L. Neck/shoulder pain and low back pain among school teachers in China, prevalence and risk factors. BMC Public Health; 2012; 12(1): 789-796.

9. Nejati, P., Lotfian, S., Moezy, A., \& Nejati, M. The Study of Correlation Between Forward Head Posture and Neck Pain. International Journal of Occupational Medicine and Environmental Health; 2015; 28(2): 8.

10. Magee, D. J. Orthopedic Physical Assessment Sixth Edition. St. Louis, Missouri: Elsevier Saunders. 2014.

11. Kim, T.-W., an, D., Lee, H., Jeong, H., Kim, D.-H., \& Sung, yun-H. Effects of elastic band exercise on subjects with rounded shoulder posture and forward head posture. The Journal of Physical Therapy Science; 2016; 28: 17331737.

12. Vakili, L., Halabchi, F., Mansournia, M. A., Khami, M. R., Irandoost, S., \& Alizadeh, Z. Prevalence of common postural disorders among academic dental staff. Asian Journal of Sports Medicine; 2016; 7(2): 2-6.

13. Rahman, M. N. A., Masood, I., Awalludin, N. F., \& Hassan, M. F. Ergonomic risk factors associated with muscuslokeletal disorders in computer workstation. International Journal of Applied Engineering Research; 2017; 12(7): 1355-1359.

14. Nejati, P., Lotfian, S., Moezy, A., \& Nejati, M. The relationship of forward head posture and rounded shoulders with neck pain in Iranian office workers. Medical Journal of the Islamic Republic of Iran; 2014; 28(26): 1-7.

15. Page, P., Frank, C. C., \& Lardner, R. Asessment and Treatment of Muscle Imbalance: The Janda Approach. United States of America: Human Kinetics. 2010

16. Go, S.-U., \& Lee, B.-H. Effects of manual therapy on shoulder pain in office workers. Journal of Physical Therapy 
Science; 2016; 28(9): 2422-2425.

17. Alrowayeh, H. N., Alshatti, T. A., Aljadi, S. H., Fares, M., Alshamire, M. M., \& Alwazan, Sahar S. Prevalence, characteristics, and impacts of work-related musculoskeletal disorders: A survey among physical therapists in the State of Kuwait. BMC Musculoskeletal Disorders; 2010 11: 116.

18. Kim, E-K., Kim J. S. Correlation between rounded shoulder posture, neck disability indicies, and degree of forward head posture. J. Phys. Ther. Sci; 2016 28: 2929-2932.

19. Nijs, J., Roussel, N., Vermeulen, K., \& Souvereyns, G. Scapular positioning in patients with shoulder pain: A study examining the reliability and clinical importance of 3 clinical tests. Archives of Physical Medicine and Rehabilitation; 2005; 86(7): 1349-1355.

20. Greenfield, B., Catlin, P. A., Coats, P. W., Green, E., McDonald, J. J., \& North, C. Posture in Patients With Shoulder Overuse Injuries and Healthy Individuals. Journal of Orthopaedic \& Sports Physical Therapy; 2995; 21(5): 287-295.

21. Rivai, W. T., Ekawati, \& Jayanti, S. Hubungan Tingkat Risiko Ergonomi dan Masa Kerja dengan Keluhan Muskuloskeletal pada Pekerja Pemecah Batu. Jurnal Kesehatan Masyarakat (e-journal); 2014; 2(3): 227-231.

22. Ranasinghe, P., Perera, Y. S., Lamabadusuriya, D. A., Kulatunga, S., Jayawardana, N., Rajapakse, S., \& Katulanda, P. Work related complaints of neck, shoulder and arm among computer office workers: A cross-sectional evaluation of prevalence and risk factors in a developing country. Environmental Health: A Global Access Science Source; 2011 10(1): 1-9.

23. Herin, F., Vézina, M., Thaon, S., Soulat, J-M., Paris, C. Predictor of chronic shoulder painafter 5 years in a working population. Pain; 2012; 153: 2253-2259.

24. Bodin, J., Ha, C., Sérazin, C., Descatha, A., Leclerc, A., Goldberg, M., \& Roquelaure, Y. Effects of individual and work-related factors on incidence of shoulder pain in a large working population. Journal of Occupational Health; 2012; 54(4): 278-288.

25. AASA, U., Barnekow-Bergvist, M., Angquist, K.-A., \& Brulin, C. Relationship between Work-related Factors and Disordes in the Neck-shoulder and Low-back Region among Female and Male Ambulance Personnel. $J$ Occup Health; 2005; 47: 481-489.

26. Ming, Z., Närhi, M., \& Siivola, J. Neck and shoulder pain related to computer use. Pathophysiology; 2004; 11(1): $51-56$. 